\title{
Comparative Histological Study on the Therapeutic Effect of Green Tea and Stem Cells in Alzheimer's Disease Complicating Experimentally Induced Diabetes
}

\author{
Hend Shafik Bassiony ${ }^{1}$, Maha Baligh Zickri ${ }^{1}$, Hala Gabr Metwally ${ }^{2}$, Hala Ahmed Elsherif ${ }^{1}$, \\ Sarah Mohammed Alghandour ${ }^{1}$, Wael $\mathrm{Sakr}^{3}$ \\ Departments of ${ }^{1}$ Histology, ${ }^{2}$ Clinical Pathology, Faculty of Medicine, Cairo University, Cairo, \\ ${ }^{3}$ Department of General Surgery, Faculty of Medicine, Beni-Suef University, Beni-Suef, Egypt
}

Background and Objectives: Alzheimer's disease $(\mathrm{AD})$ is a devastating neurodegenerative disorder. Increasing evidence implicates diabetes mellitus (DM) as a risk factor for $\mathrm{AD}$. Green tea (GT) has several beneficial effects attributed to its anti-oxidant phenolic compounds. Adipose tissue is a rich source of adipose-derived mesenchymal stem cells (ADSCs). This study was designed to evaluate and compare the possible therapeutic effect of green tea extract (GTE) and $\mathrm{ADSC}$ on $\mathrm{AD}$ complicating induced $\mathrm{DM}$ in male rat.

Methods: 31 adult male albino rats were divided into 5 groups. Group I (Control), Group II received GTE, $50 \mathrm{mg} / \mathrm{kg}$ daily orally for 4 weeks, Group III received a single intraperitoneal injection of Streptozotocin (STZ), $50 \mathrm{mg} / \mathrm{kg}$, Group IV: received STZ followed by GTE and Group V: received STZ followed by human ADSCs (hADSCs) intravenously. Results: Multiple acidophilic masses, deformed neurons, Congo red +ve masses and Caspase 3 +ve neurons were seen in group III, became few in group IV and occasional in group V. Multiple Prussian blue + ve cells were detected in group V. Some CD44 +ve cells were noticed in group III, became multiple in groups IV and V. The mean area of neurons exhibiting acidophilic cytoplasm, mean area of amyloid plaques and mean area $\%$ of Caspase $3+$ ve cells indicated a significant increase in group III. The mean area \% of CD44 +ve cells recorded a significant increase in group IV.

Conclusions: hADSCs exerted a more marked therapeutic effect on the neurodegenerative changes complicating DM and corresponding to $\mathrm{AD}$.

Keywords: Alzheimer's disease, Diabetes mellitus, Streptozotocin, Green tea extract, Adipose-derived mesenchymal stem cells

\footnotetext{
Accepted for publication July 8, 2015, Published online November 30, 2015 Correspondence to Maha Baligh Zickri

Departments of Histology, Faculty of Medicine, Cairo University, Cairo, Egypta

Tel: +201223955078, Fax: +20235381183/+20235381760

E-mail:maha_kaah@yahoo.com

(a) This is an open-access article distributed under the terms of the Creative Commons Attribution Non-Commercial License (http://creativecommons.org/ licenses/by-nc/4.0/), which permits unrestricted non-commercial use, distribution, and reproduction in any medium, provided the original work is properly cited.
}

\section{Introduction}

Alzheimer's disease $(\mathrm{AD})$ is a progressive neurodegenerative disorder. Currently, it is the most common type of dementia in the world. It is estimated to affect 35.6 million patients worldwide. The number of patients who suffer from $\mathrm{AD}$ and other dementias worldwide is estimated to rise to 115.4 million by 2050 (1).

Alzheimer's disease is characterized by abnormal protein deposits in the brain; amyloid $\beta$ (A $\beta$ ) peptides and tau-protein fibers forming neurofibrillary tangles (NFTs). Risk factors for development and progression of $\mathrm{AD}$ were 
delineated, generating abundant theories on preventive measures and therapies (2).

Recently, many studies have indicated that diabetes mellitus (DM) affects the central nervous system. Epidemiological surveys suggested that DM is associated with an increased prevalence of $\mathrm{AD}$. Therefore, some literatures have proposed that $\mathrm{AD}$ represents "type 3 diabetes" (3).

Green Tea (GT) is one of the most popular beverages consumed around the world. Green tea extract (GTE) can be made from the leaves and used as medicine and is reported to contain polyphenols which play a key role in prevention and treatment of many diseases. Epigallocatechin-3-gallate (EGCG) is the most active and abundant polyphenol in GT, known for its potent antioxidant properties in several studies in animal and cell culture models (4).

Mesenchymal stem cells (MSCs) are an ideal candidate for cellular therapy that could be used in the treatment of degenerative diseases especially the neurodegenerative disorders (5). Adipose-derived mesenchymal stem cells (ADSCs) can be harvested in large numbers with low donor-site morbidity. Numerous studies have provided preclinical data on the safety and efficacy of ADSCs, supporting their use in future clinical applications (6).

This study was designed to evaluate and compare the possible therapeutic effect of both GTE and hADSCs on $\mathrm{AD}$ complicating induced $\mathrm{DM}$ in adult male albino rats.

\section{Materials and Methods}

\section{Drugs}

Streptozotocin (STZ): Sigma Company (St. Louis, Mo, USA) in a powder form as $1 \mathrm{~g}$ vial. The required dose was weighed using a digital scale and dissolved in citrate buffer.

Green Tea Extract (GTE): Technomad, El Obour for Modern Pharmaceutical Industries (El Obour City, Egypt) in the form of $200 \mathrm{mg}$ tablets. The tablets were crushed and the required dose was weighed using a digital scale and dissolved in saline.

\section{Experimental design}

Thirty one adult male albino rats with average body weight 200 grams were housed in hygienic stainless steel cages and kept in a clean well ventilated room in the Animal Houses of Histology and Physiology Departments, Faculty of Medicine, Cairo University. They were allowed food and water ad libitum. All procedures were held according to the guidelines of Cairo University. The rats were divided into the following groups:

Group I (Control Group): Eight rats were subdivided equally into four subgroups, (Ia, Ib, Ic and Id) that corresponded to and sacrificed with the experimental groups II, III, IV and V respectively.

- Subgroup Ia: 2 rats were left for 4 weeks without therapy then received $0.5 \mathrm{ml}$ of oral saline daily for the next 4 weeks using a syringe without a needle.

- Subgroup Ib: 2 rats received a single intraperitoneal (IP) injection of $0.5 \mathrm{ml}$ citrate buffer.

- Subgroup Ic: 2 rats received a single IP injection of $0.5 \mathrm{ml}$ citrate buffer. 4 weeks later, they were given $0.5 \mathrm{ml}$ of oral saline daily for 4 weeks.

- Subgroup Id: 2 rats received a single IP injection of $0.5 \mathrm{ml}$ citrate buffer. 4 weeks later, they were given $0.5 \mathrm{ml}$ of phosphate buffered saline (PBS) intravenously (I.V.) via tail vein twice with 24 hours interval.

All rats of this group were sacrificed 8 weeks from the start of the experiment.

Group II (GTE Group): Five rats were left for 4 weeks without therapy. They received GTE at a dose of $50 \mathrm{mg} / \mathrm{kg}$ body weight (4) dissolved in $0.5 \mathrm{ml}$ saline for each rat daily orally using a syringe without a needle for the next 4 weeks. The animals were sacrificed 8 weeks from the beginning of the experiment.

Group III (Diabetic Group): Eight rats received a single IP injection of STZ at a dose of $50 \mathrm{mg} / \mathrm{kg}$ body weight (7) dissolved in $0.5 \mathrm{ml}$ citrate buffer for each rat. Three weeks following STZ injection, diabetes was confirmed by measuring the blood glucose level in the Biochemistry Department, Faculty of Medicine, Cairo University. The animals were considered diabetic if their blood glucose level was higher than $200 \mathrm{mg} / \mathrm{dl}$. Neurodegenerative changes corresponding to $\mathrm{AD}$ were confirmed by histological examination in three rats on the fourth week (8). The animals were left for 4 weeks without treatment and sacrificed 8 weeks (8) following STZ injection.

Group IV (Diabetic Group Administrating GTE): Diabetes was induced and confirmed in 5 rats as in group III. Four weeks following STZ injection, the rats received GTE by the same route and at the same dose as in group II. The animals were sacrificed 8 weeks following STZ injection.

Group V (Diabetic Group Injected with hADSCs): Diabetes was induced and confirmed in 5 rats as in group III. Four weeks following STZ injection, $0.5 \mathrm{ml}$ of cultured and labeled hADSCs suspended in PBS were injected in the tail vein (9) on two successive days. Stem cells (SCs) were isolated from abdominal fat that was surgically obtained by liposuction procedure performed at the operation theatre. Stem cell isolation, culture, labeling and phenotyping were performed at the Clinical Pathology Department, Faculty of Medicine, Cairo University. The 
animals were sacrificed 8 weeks from STZ injection.

Adipose Tissue Collection (10): The harvested adipose tissue was washed with $20 \mathrm{~mL}$ of PBS 3 times, cut into small pieces, and the extracellular matrix was digested with $0.1 \%$ collagenase solution (Sigma-Aldrich, St. Louis, MO, USA) with shaking at $37^{\circ} \mathrm{C}$ for $40 \mathrm{~min}$. After adding Dulbecco's modified Eagle's medium (DMEM), 1\% penicillin (Sigma-Aldrich, St. Louis, MO, USA), and 10\% fetal bovine serum (FBS) (Sigma-Aldrich, St. Louis, MO, USA), it was centrifuged at $1,500 \mathrm{rpm}$ for $3 \mathrm{~min}$ and washed using DMEM with FBS 3 times.

ADSCs Isolation and Culture (10): The supernatant was discarded and the pellet resuspended and filtered through a $100 \mu \mathrm{m}$ cell strainer to remove undigested tissue fragments. The cells were then resuspended in cell culture medium, consisting of DMEM and supplemented by $1 \%$ penicillin, in addition to $10 \% \mathrm{FBS}$. Cell cultures were maintained in a standard humidified incubator, saturated by $5 \% \mathrm{CO}_{2}$, at $37^{\circ} \mathrm{C}$. Twenty-four hours later, the nonadherent cells were eliminated by changing the culture medium. The adherent ADSCs were maintained until passage 3 in the medium.

Subculture (11): The media were replaced after 3 days until putative ADSCs colonies were noted. The cultures were inspected daily for formation of adherent spindle-shaped fibroblastoid cell colonies. Sub-culturing was done by chemical detachment using $0.04 \%$ trypsin or by mechanically picking fibroblastoid colonies. Later, when cell numbers allowed, expansion was done in $25 \mathrm{~cm}^{2}$ or $75 \mathrm{~cm}^{2}$ tissue culture flasks. Cells were seeded at densities of 3000 25000 cells per $\mathrm{cm}^{2}$.

Flow cytometry (12): Positive and negative human MSCs (HMSCs) markers of the separated cells were assessed on a Fluorescence Activated Cell Sorter (FACS) flow cytometer (Coulter Epics Elite, Miami, FL, USA). HMSC were trypsinized and washed twice with PBS. A total number of $1 \times 10^{5}$ HMSC were used for each run. To evaluate the HMSC marker profile, cells were incubated in $100 \mu \mathrm{L}$ of PBS with $3 \mu \mathrm{L}$ of CD44 MSCs marker or appropriate isotype controls for $20 \mathrm{~min}$ at room temperature. Antibody $(\mathrm{Ab})$ concentration was $0.1 \mathrm{mg} \mathrm{mL} \mathrm{m}^{-1}$. Cells were washed twice with PBS and finally diluted in $200 \mu \mathrm{L}$ of PBS. The expression of surface marker was assessed by the mean fluorescence. CD133 (early hematopoietic \& endothelial progenitor stem cells marker) and CD45 (panleucocytic marker) were also used. The percentage of cells positive for CD44 was determined by subtracting the percentage of cells stained non-specifically with isotype control antibodies.

Labeling (13): Labeling of ADSCs was performed by incubation with ferumoxides injectable solution (25 microgramFe/ml, Feridex, Berlex Laboratories) in culture medium for 24 hours with 375 nanogram $/ \mathrm{ml}$ polylysine added 1 hour before cell incubation. Labeling was histologically assessed using Prussian blue. Feridex labeled HMSCs were washed in PBS, trypsinized, washed and resuspended in $0.01 \mathrm{Mol} / \mathrm{L}$ PBS at concentration of $1 \times 1000000$ cells $/ \mathrm{ml}$.

Cell viability analysis (14): Cell viability was done using trypan blue dye exclusion test. This method is based on the principle that viable cells do not take up certain dyes, whereas dead cells do.

The rats belonging to experimental groups and corresponding control rats were sacrificed by ether inhalation. The skull was opened by bone cutter at the temporal regions. The brain was exposed and immediately dissected out, the frontal lobes (3) were separated following placing in $10 \%$ formol saline for 24 hours at room temperature (RT). Frontal lobe specimens were embedded into paraffin wax. Coronal sections (3) of $5 \mu \mathrm{m}$ thickness were prepared and subjected to following studies:

Histological Study: Hematoxylin \& Eosin (H\&E) stain (15). Histochemical Study

a) Congo red (CR) stain to demonstrate the amyloid plaques (16).

b) Prussian blue $(\mathrm{Pb})$ stain to demonstrate the ADSCs labeled with iron oxide (17).

Immunohistochemical Study (18)

a) Caspase $3 \mathrm{Ab}$ to detect apoptotic cells (19). $7 \mathrm{ml}$ prediluted rabbit polyclonal 1ry Ab (RB-1197-R7) (LabVision Corporation, USA) stored at $2 \sim 8^{\circ} \mathrm{C}$.

b) $\mathrm{CD} 44 \mathrm{Ab}$ to detect the endogenous and exogenous MSCs (20). $7 \mathrm{ml}$ prediluted rabbit monoclonal lry Ab (IW-PA1021) (IHC World, Ellicott City, USA) stored at $2 \sim 8^{\circ} \mathrm{C}$.

The primary $\mathrm{Ab}$ was applied to the sections, incubation took place in humidity chamber for 60 minutes at RT for both markers. The + ve tissue control was a specimen of human tonsil. Caspase 3 +ve cells showed cytoplasmic reaction while CD44 + ve cells showed membranous reaction. The -ve tissue control was processed in the same way, but omitting the step of 1ry Ab.

Morphometric Study: Using Leica Qwin 500 LTD (Cambridge UK) computer assisted image analyzer. The area of neurons exhibiting acidophilic cytoplasm and that of amyloid plaques were measured. The measurements were done in 10 low power fields (LPF) using interactive measurements menu. Area \% of Caspase $3+$ ve cells and CD44 +ve cells were measured. The measurements were done in 10 high power fields (HPF) using binary mode. 
Statistical analysis (21): Quantitative data were summarized as means and standard deviations (SD) and compared using one-way analysis-of-variance (ANOVA). p-values $<0.05$ were considered statistically significant. Calculations were made on SPSS software version 16 .

\section{Results}

\section{Histological results}

Haematoxylin and Eosin (H\&E) Stained Sections: In group I, the external pyramidal (EP) layer demonstrated pyramidal cells with typical pyramid shape and an apex of thick branching dendrite, stellate cells with dendrites projecting for short distances in all directions and granule cells with pale nuclei and minimal cytoplasm. Microglia had elongated darkly stained nuclei (Fig. 1A). Internal pyramidal (IP) layer demonstrated larger pyramidal cells, smaller numbers of stellate cells, granule cells, as well as astrocytes which had pale nuclei (Fig. 1B).

In group III, the EP layer showed multiple deformed shrunken neurons, multiple neurons exhibiting dark nuclei and acidophilic cytoplasm with occasional fusion of the neurons. Numerous dividing microglia were observed (Fig. 2A). Some fields recruited large acidophilic masses overlied by spindle cells and round dark nuclei. Multiple deformed shrunken neurons and multiple microglial cells were noticed around these masses (Fig. 2B). In the IP layer, acidophilic masses exhibiting dark nuclei were demonstrated. Occasional masses revealed margination of the nuclei or fusion. In addition, wide areas of vacuolated neuropil, dividing microglia and normal granule cells were noticed (Fig. 2C).

In group IV, the EP layer demonstrated few neurons exhibiting acidophilic cytoplasm and dark nuclei, few deformed and shrunken neurons and multiple normal pyramidal cells. Occasionally, small multinucleated acidophilic masses were noticed compared to group III (Fig. 3A). In group V, occasional neurons exhibiting acidophilic cytoplasm, dark nucleus and surrounded by a clear space were demonstrated in the EP layer as well as occasional deformed neurons and predominating normal pyramidal cells compared to groups III and IV (Fig. 3B).
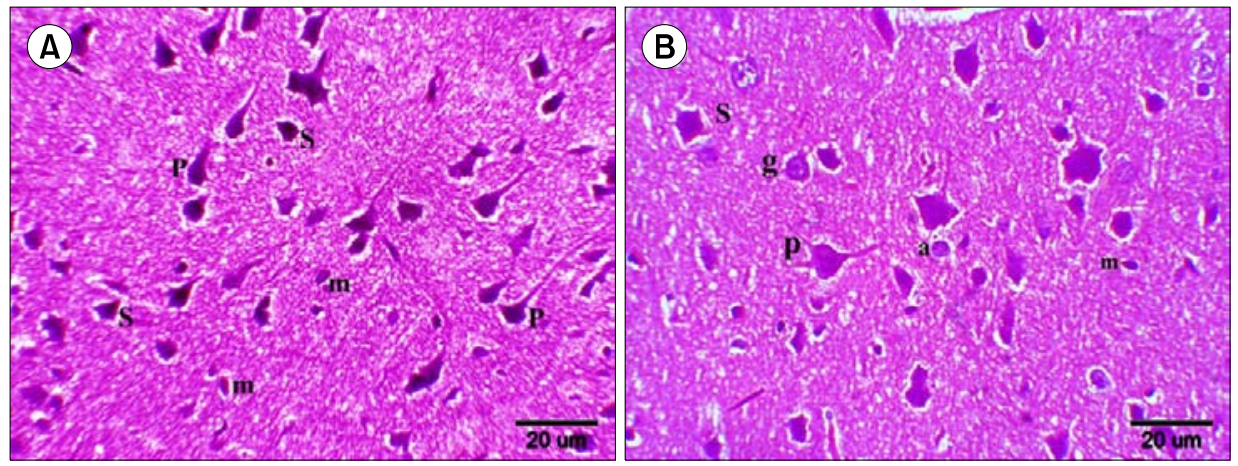

Fig. 1. H\&E (x400): Sections in the rat cerebral cortex of group I showing (A) Multiple pyramidal (p), stellate $(\mathrm{s})$ neurons and microglia $(\mathrm{m})$ in EP layer. (B) Large pyramidal (p), stellate $(\mathrm{s})$, granule cells $(\mathrm{g})$, astrocytes (a) and microglia (m) in IP layer.
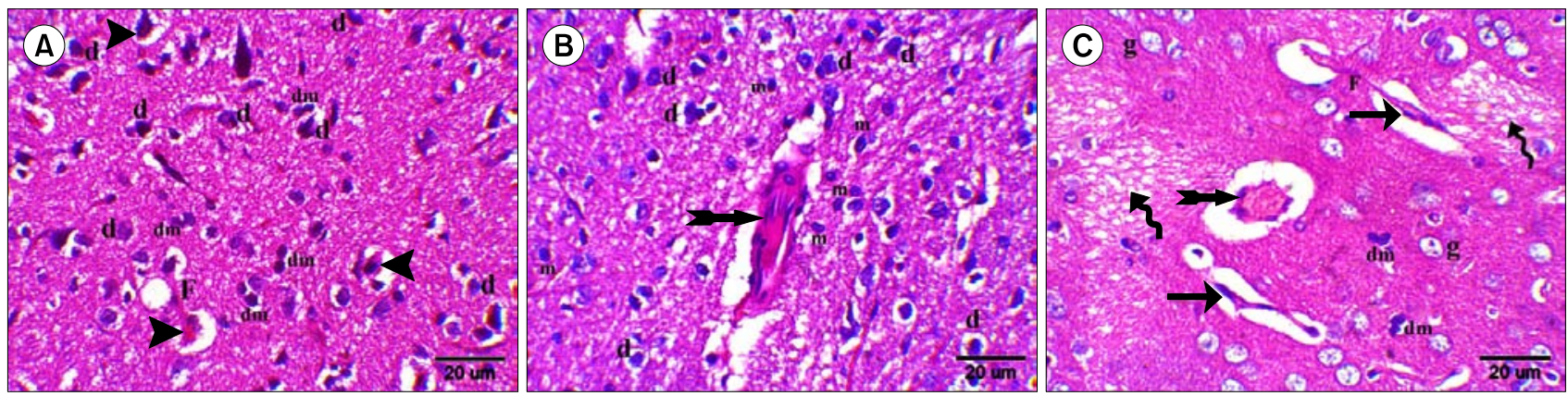

Fig. 2. H\&E (x400): Sections in the rat cerebral cortex of group III showing (A) Multiple deformed neurons (d) and multiple neurons exhibiting dark nuclei and acidophilic cytoplasm (arrowheads) in EP layer. Two of the latter neurons fuse together (F). Note multiple dividing microglia (dm). (B) A large acidophilic mass overlied by spindle cells and dark nuclei (bifid arrow), multiple deformed neurons (d) and multiple microglia (m) in EP layer. (C) Two acidophilic masses exhibiting dark nuclei (arrows), another reveals margination of nuclei (bifid arrow), fusion of two masses (F), wide areas of vacuolated neuropil (wavy arrows), dividing microglia (dm) and normal granule cells (g) in IP layer. 


\section{Histochemical results}

Congo Red (CR) Stained Sections: Group I showed dull red staining of the neurons as well as the neuropil in EP and IP layers (Fig. 4A and B). Group III showed multiple strongly + ve masses with variable sizes, small and large in EP and IP layers (Fig. 4C and D). Group IV demonstrated few strongly + ve smaller masses in EP layer compared to those of group III (Fig. 4E). Occasional strongly + ve neurons were seen in EP layer of group $\mathrm{V}$ compared to groups III and IV (Fig. 4F).
Prussian Blue (Pb) Stained Sections: Group I demonstrated -ve staining with $\mathrm{Pb}$ among pyramidal and stellate cells in EP layer (Fig. 5A). Group V showed some $\mathrm{Pb}+\mathrm{ve}$ cells in the neuropil near blood vessels in the EP layer (Fig. 5B).

\section{Immunohistochemical results}

Anti-Caspase 3 Immunostained Sections: Group I showed -ve immunostaining among the pyramidal, stellate neurons and in the endothelial lining of blood vessels
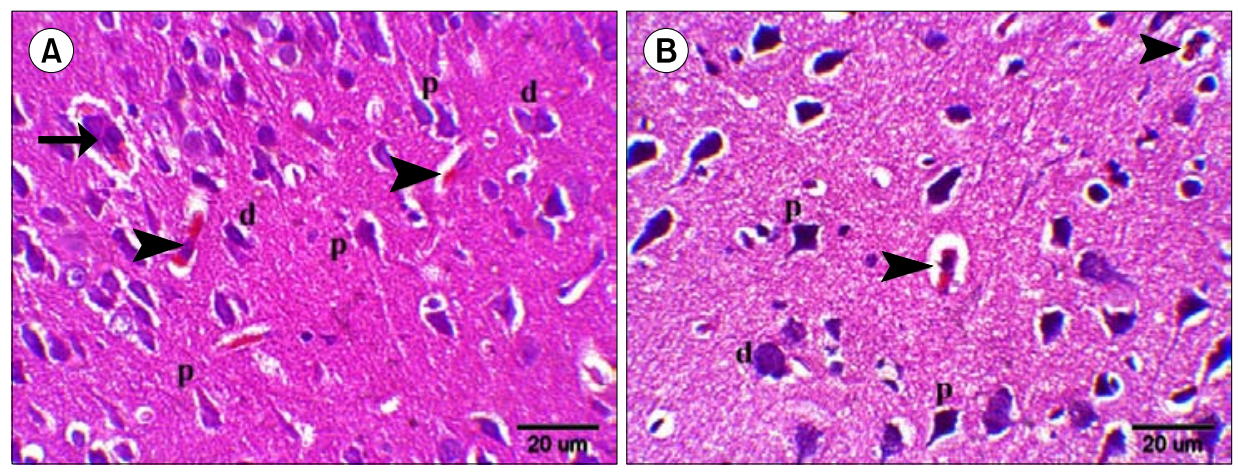

Fig. 3. H\&E (x400): Sections in the rat cerebral cortex in EP layer of (A) Group IV showing a small multinucleated acidophilic mass (arrow), few deformed neurons (d), few neurons exhibiting acidophilic cytoplasm and dark nuclei (arrowheads) and multiple normal pyramidal cells (p). (B) Group V showing two neurons exhibiting acidophilic cytoplasm and dark nucleus (arrowheads), a deformed neuron (d) and multiple normal pyramidal cells (p).
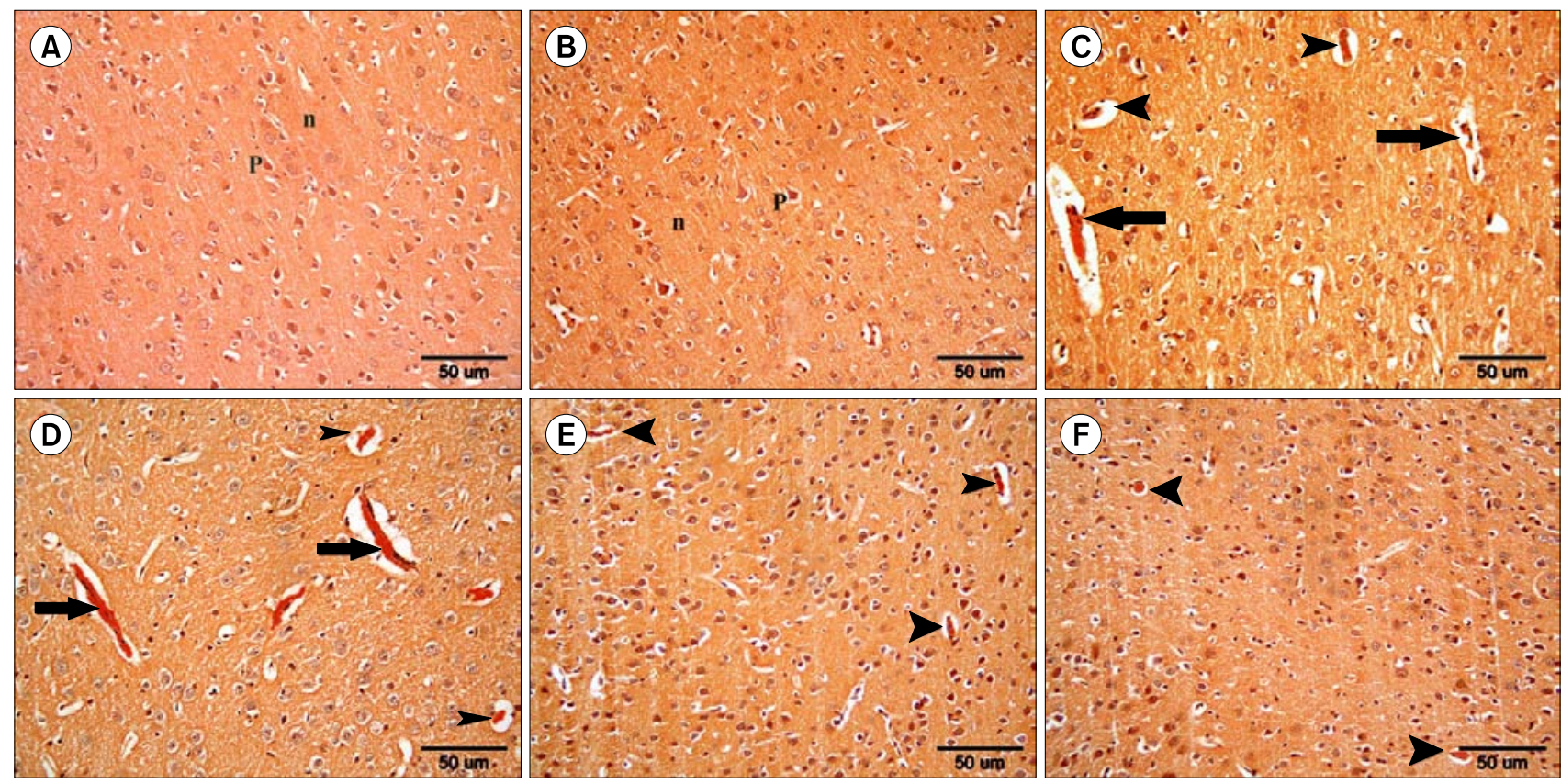

Fig. 4. Congo red (x200): Sections in the rat cerebral cortex of (A, B) Group I showing dull red staining of pyramidal cells (p) and the neuropil (n) in EP and IP layers respectively. (C, D) Group III showing multiple strongly + ve masses, small (arrowheads) and large (arrows) in EP and IP layers respectively. (E, F) Groups IV and V showing few strongly + ve small masses (arrowheads) and two strongly + ve neurons (arrowheads) respectively in EP layer. 

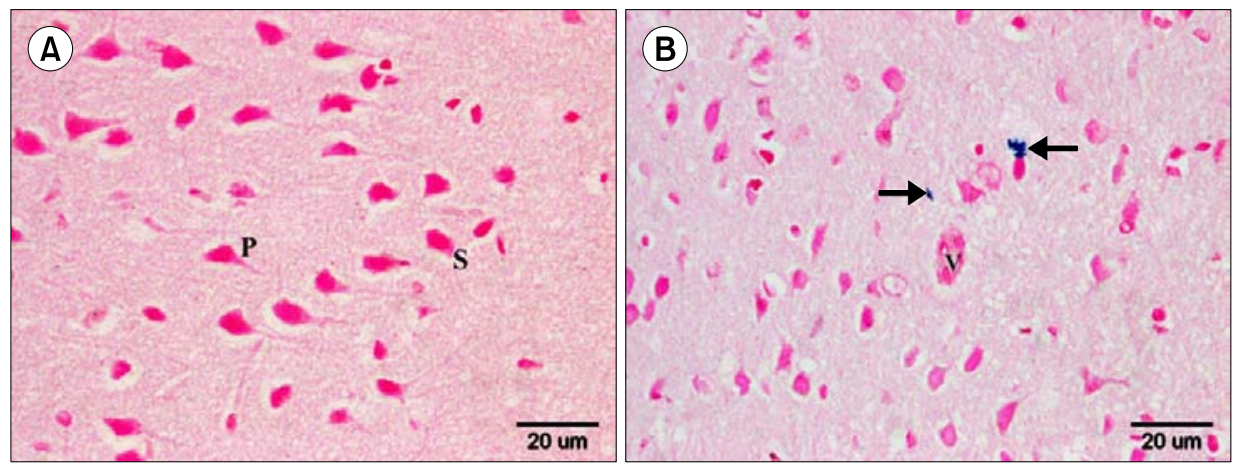

Fig. 5. Prussian blue (x400): Sections in the rat cerebral cortex in EP layer of (A) Group I showing - ve reaction among pyramidal $(p)$ and stellate (s) cells. (B) Group V showing some + ve cells in the neuropil near (arrows) a blood vessel (v).
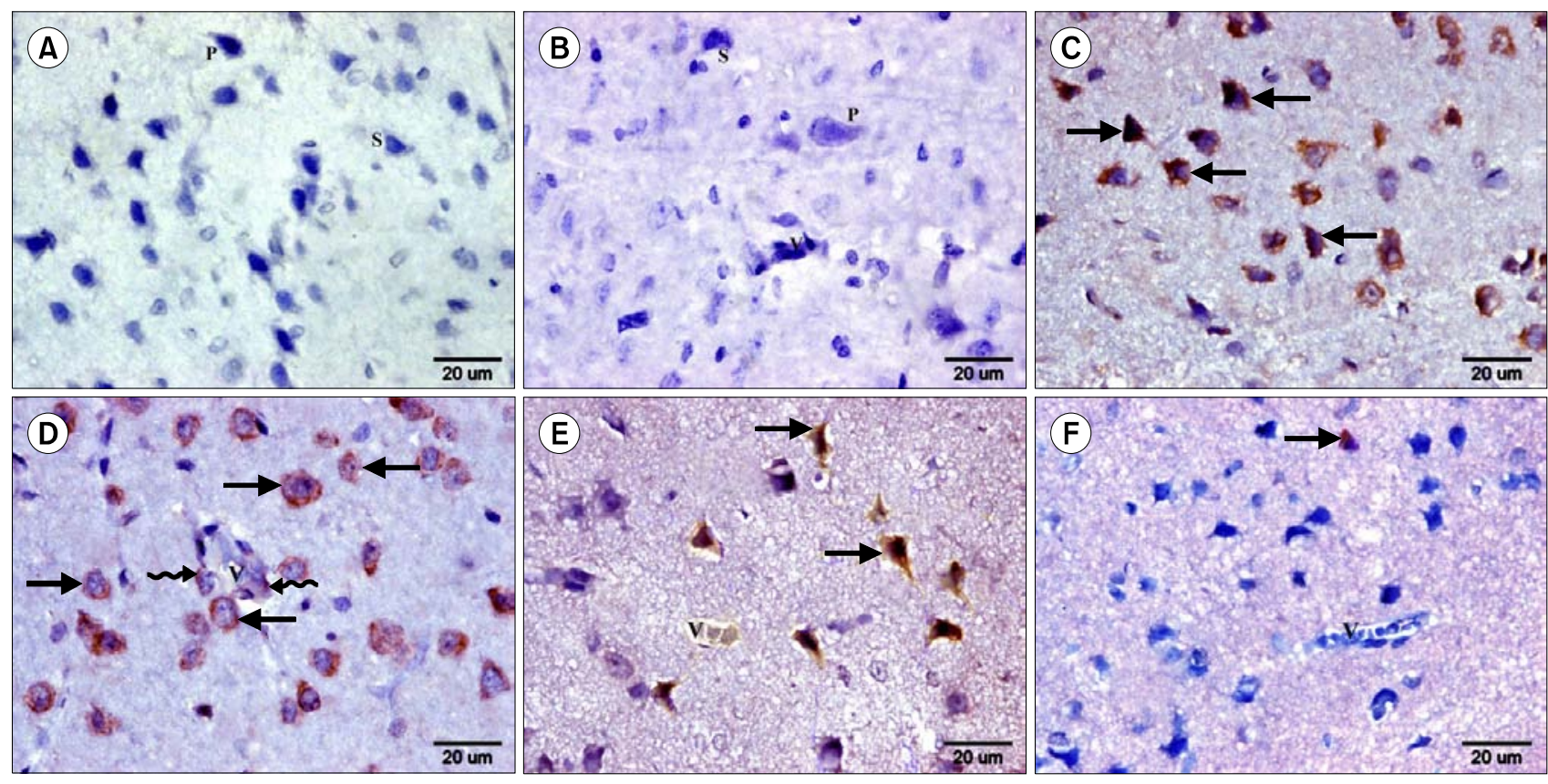

Fig. 6. Caspase 3 (x400): Sections in the rat cerebral cortex of $(A, B)$ Group I showing -ve immunoreaction among pyramidal (p) and stellate (s) cells in EP and IP layers respectively and in the endothelial lining of a blood vessel (v) in IP layer. (C, D) Group III showing numerous + ve neurons (arrows) in the EP and IP layers respectively and + ve endothelial lining (wavy arrow) in a blood vessel in IP layer. (E, F) Groups IV and V showing few + ve neurons (arrows) and a + ve neuron (arrow) respectively in EP layer around a blood vessel $(v)$.

in the EP and IP layers (Fig. 6A and B). In group III, numerous Caspase $3+$ ve neurons were evident in the EP and IP layers. + ve endothelial lining was noted in some blood vessels (Fig. 6C and D). Group IV demonstrated few Caspase 3 +ve neurons around blood vessels in EP layer (Fig. 6E). Occasional Caspase $3+$ ve neurons were seen in group $\mathrm{V}$ in EP layer. - ve endothelial lining was noticed in all blood vessels (Fig. 6F).

Anti-CD44 Immunostained Sections: Group I showed negative immunoreactivity among the neurons and the neuropil in EP and IP layers. Group III showed some CD44 + ve cells overlying masses in the neuropil and inside blood vessels in EP layer (Fig. 7A). Group IV showed multiple CD44 + ve cells fused with some neurons, overlying few masses and in the neuropil of EP layer (Fig. 7B). In group $\mathrm{V}$, multiple CD44 + ve cells were recruited inside blood vessels and in the neuropil in the EP layer (Fig. 7C).

Sections in rat cerebral cortex of group II showed a histological, histochemical and immunohistochemical appearance comparable to group I.

\section{Morphometric results}

Table 1: Mean area \pm SD of neurons exhibiting acidophilic cytoplasm, area of amyloid plaques, area \% of Caspase + ve cells and area \% of CD44 + ve cells in con- 

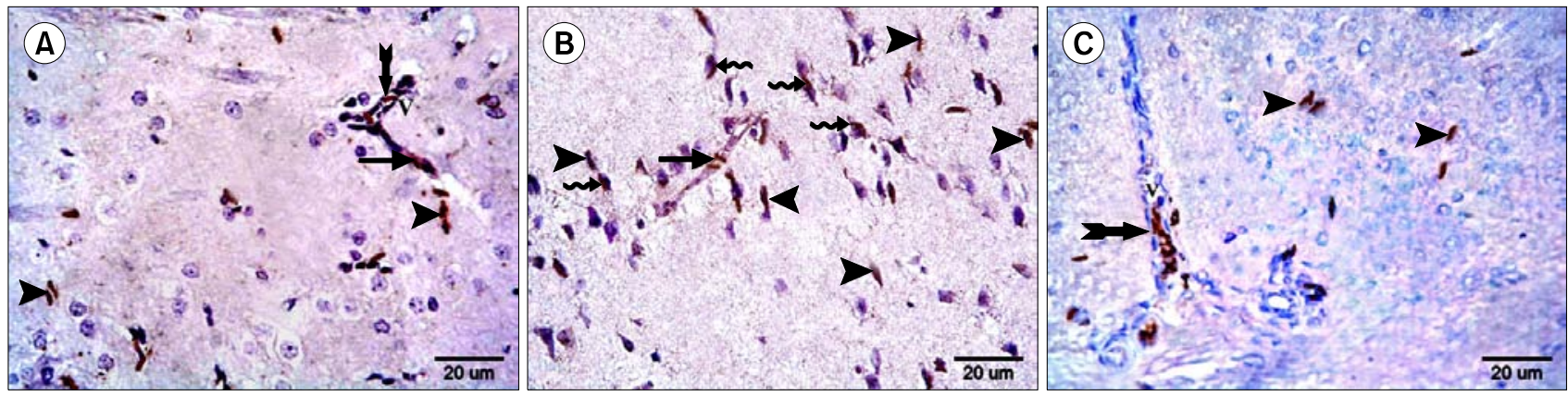

Fig. 7. CD44 (x400): Sections in the rat cerebral cortex in EP layer of (A) Group III showing some + ve cells, overlying a mass (arrow), in the neuropil (arrowheads) and inside (bifid arrow) a blood vessel (V). (B) Group IV showing multiple + ve cells fused with some neurons (wavy arrows), overlying a mass (arrow) and in the neuropil (arrowheads). (C) Group $\mathrm{V}$ showing multiple + ve cells, in the neuropil (arrowheads) and inside (bifid arrow) a blood vessel (V).

Table 1. Mean area \pm SD of neurons exhibiting acidophilic cytoplasm, area of amyloid plaques, area $\%$ of Caspase + ve cells and area $\%$ of CD44 + ve cells in control and experimental groups

\begin{tabular}{lcccc}
\hline Group & $\begin{array}{c}\text { Area of neurons exhibiting } \\
\text { acidophilic cytoplasm }\end{array}$ & $\begin{array}{c}\text { Area of amyloid } \\
\text { plaques }\end{array}$ & $\begin{array}{c}\text { Area \% of } \\
\text { Caspase }+ \text { ve cells }\end{array}$ & $\begin{array}{c}\text { Area of } \\
\text { CD44 }+ \text { ve cells }\end{array}$ \\
\hline Group I & - & - & - & - \\
Group II & - & - & - & - \\
Group III & $79.26 \pm 12.53^{*}$ & $384.41 \pm 82.36^{*}$ & $8.00 \pm 0.75^{*}$ & $1.21 \pm 0.37$ \\
Group IV & $15.12 \pm 4.24 \bullet$ & $57.58 \pm 7.52 \bullet$ & $1.40 \pm 0.33 \bullet$ & $4.18 \pm 0.79$ \\
Group V & $4.84 \pm 1.55$ & $10.47 \pm 1.13$ & $0.18 \pm 0.04$ & $1.07 \pm 0.30$ \\
\hline
\end{tabular}

*Significant compared to groups IV and $\mathrm{V}(\mathrm{p}<0.05)$, $\bullet$ Significant compared to group and $\mathrm{V}(\mathrm{p}<0.05)$, $\bullet$ Significant compared to groups III and $\mathrm{V}(\mathrm{p}<0.05)$

trol and experimental groups.

\section{Discussion}

The present study demonstrated the ameliorating effect of GTE and ADSCs administration on the neurodegenerative changes complicating diabetes and corresponding to $\mathrm{AD}$ following STZ-induced $\mathrm{DM}$ in rats. This was evidenced by histological, histochemical, immunohistochemical, morphometric and statistical results.

Accumulating evidence has demonstrated that hyperglycemia may play an important role in the pathophysiology of cognitive dysfunction and cerebral lesions in diabetes. Furthermore, clinical and epidemiological studies have provided direct evidence of a link between DM and $\mathrm{AD}$ (22). The optimal dose of STZ that has been reported to produce maximum diabetic conditions in rats is (50 to $75 \mathrm{mg} / \mathrm{kg}$, IP) (7).

In the present study, sections in rat frontal cortex of group II showed a histological picture comparable to group I. It was reported that the frontal cortex is a brain structure that plays an important role in cognition and is known to be affected in $\mathrm{AD}$ (23).
In the current work, group III showed multiple deformed and multiple neurons with acidophilic cytoplasm and occasional fusion in the EP layer, which can suggest the initiation of mass or plaque formation. These observations indicated apoptosis and degeneration and were supported by a significant increase in the mean area of neurons exhibiting acidophilic cytoplasm in group III compared to the groups IV and V. It was stated that the classic appearance of neuron degeneration is seen in the process known as "acute eosinophilic neuron degeneration." The degenerating neurons, sometimes referred to as "red dead neurons", are characterized by cell body shrinkage, loss of Nissl substance, intensely stained eosinophilic cytoplasm. In addition, small/shrunken darkly stained pyknotic nucleus that may eventually fragment and undergo karyorrhexis exists (24). It was stated that pyramidal cells appear to be the main substrate for neurodegenerative changes in $\mathrm{AD}$ (25). Pyramidal cortical neurons in EP layer are the principal neurons involved in corticocortical circuits, that mediate many cognitive functions and may be selectively targeted in neurodegenerative diseases (26). It was added that several studies have shown that $\mathrm{A} \beta$ peptide promotes hyperphosphorylation and aggregation of 
microtubule-associated protein tau into NFTs (27) causing severe cellular burden resulting in neuronal damage (28).

Alterations in insulin function and glucose homoeostasis in the peripheral tissues may affect brain insulin and its receptor functions, promoting the production of $\mathrm{A}$ $\beta$ and inducing tau phosphorylation (22) This is in accordance with Wang et al. (3) who revealed the presence of $\mathrm{A} \beta$ immunoreactivity in the frontal cortex of diabetic rats 4 months after STZ injection. An important link between $\mathrm{DM}$ and $\mathrm{AD}$ may be related to the insulin-degrading enzyme (IDE) responsible for $\mathrm{A} \beta$ degradation, which has been reported to be decreased in the brains of $\mathrm{AD}$ patients (22).

Caspase 3-immunostained sections revealed numerous + ve neurons in the EP and IP layers. Positive endothelial cells were detected lining some blood vessels in IP layer. Further support for these results was gained from the morphometric analysis, as the mean area \% of Caspase 3 + ve cells showed a significant increase in group III compared to groups IV and V. The previous results confirmed the developing apoptotic changes. Salem et al. (29) reported that apoptosis has been associated with the pathophysiology of $\mathrm{AD}$ as $\mathrm{A} \beta$, increasing oxidative stress, metabolic impairment and DNA damage has been known to induce apoptosis. Lee et al. (30) suggested that cerebrovascular degeneration and senescent endothelial cells also contribute to the pathogenesis of $\mathrm{AD}$ by causing faulty clearance of $\mathrm{A} \beta$ peptide across the blood brain barrier (BBB).

In the present study, group III showed multiple large acidophilic masses that exhibited dark nuclei in EP and IP layers. In the EP layer, occasional masses were seen overlied by spindle cells and round dark nuclei. It can be concluded that spindle cells are mesenchymal cells. In addition, dark nuclei can be apoptotic nuclei of several degenerated neurons fusing together to form masses. In the IP layer occasional masses with margination of the nuclei were noticed which can be related to further extrusion of the nuclei. It was reported that the amyloid plaques appear first in the frontal cortex then they spread over the entire cortical region (25). They are associated with neuronal dysfunction and detectable by H\&E in cortex in $\mathrm{AD}$ (31). Bonda et al. (28) reported that oxidative stress is a prominent and early feature of $\mathrm{AD}$ and the amyloid plaques and NFTs may be an adaptation in response to elevated oxidative stress.

Congo red staining confirmed the amyloid nature of the masses in EP and IP layers. Morphometric results showed a significant increase in the mean area of amyloid plaques in group III compared to groups IV and V. Khairallah et al. (32) demonstrated CR positive material or plaques in cerebral sections of induced $\mathrm{AD}$ in mice. Castellani and Perry (33) confirmed that CR stain is used for identification of the beta sheet nature of amyloid plaques.

In the present work, numerous dividing microglia were observed in EP and IP layers in group III. Bhaskar et al. (34) demonstrated that $\mathrm{A} \beta$ peptide-mediated microglial activation induces toxic neuronal cell cycle events for terminally differentiated neurons via tumor-necrosis factor$\alpha(\operatorname{TNF} \alpha)$ leading to neurodegeneration.

The present work demonstrated wide areas of vacuolated neuropil in the IP layer in group III. This is in accordance with Garman (24) who stated that neuropil vacuolation develops as a result of swelling of neuronal processes.

In the present study, group IV demonstrated few neurons with acidophilic cytoplasm, few deformed neurons and multiple normal pyramidal cells, few Caspase $3+v e$ neurons, occasional acidophilic small masses and few CR strongly +ve small masses in EP layer compared to group III. A significant decrease in the mean area of neurons exhibiting acidophilic cytoplasm and that of amyloid plaques as well as the mean area \% of Caspase $3+$ ve cells compared to group III was confirmed by morphometric results. Noguchi-Shinohara et al. (35) demonstrated that daily GT consumption is significantly associated with a decreased risk of cognitive decline and dementia. EGCG is permeable to the $\mathrm{BBB}$ and exerts neuroprotective effects by inhibiting $\mathrm{A} \beta$ aggregation and induced oxidative stress.

In the current study, sections of group $\mathrm{V}$ showed occasional deformed neurons, occasional neurons with acidophilic cytoplasm in the EP layer as well as predominating normal pyramidal cells. Occasional Caspase $3+v e$ neurons and - ve endothelial lining were found in all blood vessels in addition to occasional CR strongly +ve neurons in EP layer. The previous results were supported by a significant decrease in the mean area of neurons exhibiting acidophilic cytoplasm and dark nuclei and that of amyloid plaques as well as the mean area \% of Caspase $3+$ ve cells compared to groups III and IV. Cho et al. (36) demonstrated that the transplantations of human and mouse MSCs were shown to reduce $\mathrm{A} \beta$ deposition, improve memory and alleviate the $\mathrm{AD}$ pathology in $\mathrm{AD}$ mouse models.

In the current study, $\mathrm{Pb}$ stained sections of group $\mathrm{V}$ showed some $\mathrm{Pb}+$ ve cells in the neuropil near blood vessels in the EP layer. Kim et al. (9) demonstrated that I.V. human ADSCs passed through the BBB and migrated into the brain of an $\mathrm{AD}$ mouse model, since disruption in the 
$\mathrm{BBB}$ was observed. The learning and memory greatly improved while the number of amyloid plaques decreased significantly. The authors recorded upregulation of anti-inflammatory cytokines and vascular endothelial growth factor.

In the present study, CD44-immunostained sections of group III showed some + ve cells overlying masses, which can be correlated to the masses observed in H\&E sections overlied by spindle cells. Also some +ve cells were seen in the neuropil and inside blood vessels in EP layer. Group IV showed multiple CD44 + ve cells, inside blood vessels, fused with some neurons, overlying few masses and in the neuropil in EP layer. Group V showed multiple CD44 + ve cells inside blood vessels and in the neuropil in EP layer. Morphometric analysis revealed a significant increase in the mean area \% of CD44+ve cells in group IV compared to groups III and V. This can be explained by GTE activation of endogenous MSCs compared to group III. On the other hand, the more differentiation of SCs in group $\mathrm{V}$ can refer to the higher \% in group IV.

Mesenchymal stem cells were documented to have critical roles in repairing damaged tissues. Tissue injury is associated with the activation of immune and inflammatory cells recruited by factors from apoptotic cells, necrotic cells and damaged microvasculature. Meanwhile, inflammatory mediators, such as $\mathrm{TNF} \alpha$ are often produced by phagocytes in response to damaged cells. Consequently, changes in the microenvironment result in the mobilization and differentiation of MSCs that can be tissue-resident or be recruited from the bone marrow (BM) (37). It was confirmed that endogenous SCs activation develops in GTE and amiodarone combined therapy in rats as multiple CD105 + ve cells were found in the thyroid gland confirming MSCs stimulation related to GTE therapy (38). Salem et al. (39) explored the possible therapeutic role of single I.V. injection of BM-MSCs in $\mathrm{AD}$ in an experimental model. MSCs could remove A $\beta$ plaques through their anti-apoptotic, neurogenic and immunomodulatory properties. Minuzo et al. (40) reported that CD44 marker is shared by ADSCs and MSCs.

In conclusion, the present study demonstrated that GTE and hADSCs administration following STZ-induced DM in rats, ameliorated neuron apoptosis, degeneration and amyloid plaques formation. GTE therapeutic effect can be suggested to be due to activation of endogenous MSCs beside antioxidant and anti-inflammatory effects. hADSCs may represent a future therapeutic option for $\mathrm{AD}$ patients being easily isolated and exerting a more marked therapeutic effect compared to GTE therapy.

Further research studies regarding the correlation be- tween $\mathrm{DM}$ and $\mathrm{AD}$ are recommended to illustrate the impact of DM on the CNS especially being a prominent risk factor for $\mathrm{AD}$. Combination of GTE with ADSCs could be tried as it may enhance the amelioration of the neurodegenerative changes corresponding to $\mathrm{AD}$.

\section{Potential conflict of interest}

The authors have no conflicting financial interest.

\section{References}

1. Chen Z, Zhong C. Decoding Alzheimer's disease from perturbed cerebral glucose metabolism: implications for diagnostic and therapeutic strategies. Prog Neurobiol 2013;108: 21-43

2. Huang CC, Chung CM, Leu HB, Lin LY, Chiu CC, Hsu CY, Chiang CH, Huang PH, Chen TJ, Lin SJ, Chen JW, Chan WL. Diabetes mellitus and the risk of Alzheimer's disease: a nationwide population-based study. PLoS One 2014;9:e87095-87101

3. Wang JQ, Yin J, Song YF, Zhang L, Ren YX, Wang DG, Gao LP, Jing YH. Brain aging and AD-like pathology in streptozotocin-induced diabetic rats. J Diabetes Res 2014; 2014:796840-796852

4. Namita P, Mukesh R, Vijay KJ. Camellia Sinensis (green tea): A review. Global Journal of Pharmacology 2012;6:52-59

5. Sykova E, Forostyak S. Stem cells in regenerative medicine. Laser Ther 2013;22:87-92

6. Tobita M, Orbay H, Mizuno H. Adipose-derived stem cells: current findings and future perspectives. Discov Med 2011; 11:160-170

7. Eleazu CO, Eleazu KC, Chukwuma S, Essien UN. Review of the mechanism of cell death resulting from streptozotocin challenge in experimental animals, its practical use and potential risk to humans. J Diabetes Metab Disord 2013; 12:60-66

8. Cai Z, Yan Y, Wang Y. Minocycline alleviates beta-amyloid protein and tau pathology via restraining neuroinflammation induced by diabetic metabolic disorder. Clin Interv Aging 2013;8:1089-1095

9. Kim S, Chang KA, Kim Ja, Park HG, Ra JC, Kim HS, Suh YH. The preventive and therapeutic effects of intravenous human adipose-derived stem cells in Alzheimer's disease mice. PLoS One 2012;7:e45757-45773

10. Kakudo N, Morimoto N, Ogawa T, Kusumoto K. Potential of adipose-derived stem cells for regeneration medicine: clinical application and usefulness of fat grafting. J Stem Cell Res Ther 2014;4:1000204-1000206

11. Koch TG, Heerkens T, Thomsen PD, Betts DH. Isolation of mesenchymal stem cells from equine umbilical cord blood. BMC Biotechnol 2007;7:26-34

12. Haasters F, Prall WC, Anz D, Bourquin C, Pautke C, Endres S, Mutschler W, Docheva D, Schieker M. Morphological and immunocytochemical characteristics indicate the yield of early progenitors and represent a quality con- 
trol for human mesenchymal stem cell culturing. J Anat 2009;214:759-767

13. Kraitchman DL, Heldman AW, Atalar E, Amado LC, Martin BJ, Pittenger MF, Hare JM, Bulte JW. In vivo magnetic resonance imaging of mesenchymal stem cells in myocardial infarction. Circulation 2003;107:2290-2293

14. Freshney RI. Culture of animal cells: A manual of basic technique. 3rd ed. New York: Wiley-Liss; 1994. 105-148.

15. Kiernan JA. Histological and histochemical methods : theory and practice. 3rd ed. London: Arnold; 2001. 111-162

16. Wilcock DM, Gordon MN, Morgan D. Quantification of cerebral amyloid angiopathy and parenchymal amyloid plaques with Congo red histochemical stain. Nat Protoc 2006;1:1591-1595

17. Ellis R. Perls Prussian blue Stain Protocol. IMVS division of pathology, The queen elizabeth hospital, South Australia. 2007.

18. Bancroft JD, Cook HC. Immunocytochemistry. In: Manual of histological techniques and their diagnostic applications. 2nd ed. Edinburgh: Churchill Livingstone; 1994. 263-325.

19. Yamagata M, Yamamoto A, Kako E, Kaneko N, Matsubara K, Sakai K, Sawamoto K, Ueda M. Human dental pulp-derived stem cells protect against hypoxic-ischemic brain injury in neonatal mice. Stroke 2013;44:551-554

20. Wang Q, Zhou L, Guo Y, Liu G, Cheng J, Yu H. Differentiation of human adipose-derived stem cells into neuron-like cells by Radix Angelicae Sinensis. Neural Regen Res 2013; 8:3353-3358

21. Emsley R, Dunn G, White IR. Mediation and moderation of treatment effects in randomised controlled trials of complex interventions. Stat Methods Med Res 2010;19:237-270

22. Liu J, Zhang Y, Deng X, Yin F. Geniposide decreases the level of $\mathrm{A} \beta 1-42$ in the hippocampus of streptozotocin-induced diabetic rats. Acta Biochim Biophys Sin (Shanghai) 2013;45:787-791

23. Girard SD, Baranger K, Gauthier C, Jacquet M, Bernard A, Escoffier G, Marchetti E, Khrestchatisky M, Rivera S, Roman FS. Evidence for early cognitive impairment related to frontal cortex in the 5XFAD mouse model of Alzheimer's disease. J Alzheimers Dis 2013;33:781-796

24. Garman RH. Histology of the central nervous system. Toxicol Pathol 2011;39:22-35

25. Palmer AM. Neuroprotective therapeutics for Alzheimer's disease: progress and prospects. Trends Pharmacol Sci 2011;32:141-147

26. Luebke JI, Weaver CM, Rocher AB, Rodriguez A, Crimins JL, Dickstein DL, Wearne SL, Hof PR. Dendritic vulnerability in neurodegenerative disease: insights from analyses of cortical pyramidal neurons in transgenic mouse models. Brain Struct Funct 2010;214:181-199

27. Chabrier MA, Cheng D, Castello NA, Green KN, LaFerla FM. Synergistic effects of amyloid-beta and wild-type human tau on dendritic spine loss in a floxed double trans- genic model of Alzheimer's disease. Neurobiol Dis 2014; 64:107-117

28. Bonda DJ, Wang X, Lee HG, Smith MA, Perry G, Zhu X. Neuronal failure in Alzheimer's disease: a view through the oxidative stress looking-glass. Neurosci Bull 2014;30:243-252

29. Salem AM, Sabry GM, Ahmed HH, Hussein AA, Kotob SE. Amelioration of neuroinflammation and apoptosis characterizing Alzheimer's disease by natural products. Int J Pharm Pharm Sci 2013;5(2 Suppl):87-94

30. Lee ST, Chu K, Park JE, Jung KH, Jeon D, Lim JY, Lee SK, Kim M, Roh JK. Erythropoietin improves memory function with reducing endothelial dysfunction and amyloid-beta burden in Alzheimer's disease models. J Neurochem 2012;120:115-124

31. Kovacs GG. Practical approach to diagnosis: sampling and basic stainings. In: Kovacs GG, editor. Neuropathology of neurodegenerative diseases: A practical guide. United Kingdom: Cambridge University Press; 2015. 55-69.

32. Khairallah MI, Kassem LA, Yassin NA, El Din MA, Zekri $M$, Attia M. The hematopoietic growth factor "erythropoietin" enhances the therapeutic effect of mesenchymal stem cells in Alzheimer's disease. Pak J Biol Sci 2014;17:9-21

33. Castellani RJ, Perry G. The complexities of the pathology-pathogenesis relationship in Alzheimer disease. Biochem Pharmacol 2014;88:671-676

34. Bhaskar K, Maphis N, Xu G, Varvel NH, Kokiko-Cochran ON, Weick JP, Staugaitis SM, Cardona A, Ransohoff RM, Herrup K, Lamb BT. Microglial derived tumor necrosis factor- $\alpha$ drives Alzheimer's disease-related neuronal cell cycle events. Neurobiol Dis 2014;62:273-285

35. Noguchi-Shinohara M, Yuki S, Dohmoto C, Ikeda Y, Samuraki M, Iwasa K, Yokogawa M, Asai K, Komai K, Nakamura H, Yamada M. Consumption of green tea, but not black tea or coffee, is associated with reduced risk of cognitive decline. PLoS One 2014;9:e96013-96020

36. Choi SS, Lee SR, Kim SU, Lee HJ. Alzheimer's disease and stem cell therapy. Exp Neurobiol 2014;23:45-52

37. Ma S, Xie N, Li W, Yuan B, Shi Y, Wang Y. Immunobiology of mesenchymal stem cells. Cell Death Differ 2014; 21:216-225

38. Zickri MB, Embaby A. Relation between endogenous stem cells and green tea extract in overconsumption and amiodarone induced thyroid damage in rat. Int J Stem Cells 2013;6:113-120

39. Salem AM, Ahmed HH, Atta HM, Ghazy MA, Aglan HA. Potential of bone marrow mesenchymal stem cells in management of Alzheimer's disease in female rats. Cell Biol Int 2014;38:1367-1383

40. Mizuno H, Tobita M, Uysal AC. Concise review: Adiposederived stem cells as a novel tool for future regenerative medicine. Stem Cells 2012;30:804-810 